\title{
Multifractality of the heartbeat dynamics after beating heart myocardial revascularization
}

\author{
J Ksela ${ }^{1 *}$, JM Kalisnik', V Avbelj², B Gersak ${ }^{1}$ \\ From 23rd World Congress of the World Society of Cardio-Thoracic Surgeons \\ Split, Croatia. 12-15 September 2013
}

\section{Background}

Recent studies suggest that time series of healthy human interbeat intervals belong to a special class of bio-signals displaying multifractal properties. The breakdown of multifractality was observed in congestive heart failure and angina pectoris; however, there has been no attempt to evaluate multifractal behavior before and after beating heart myocardial revascularization (off-pump CABG).

\section{Methods}

Sixty consecutive patients with isolated multivessel coronary artery disease scheduled for off-pump CABG were included in the study. Twenty-four hour Holter recordings were performed preoperatively and on the seventh postoperative day. Multifractal properties of the RR data set were determined for both, day- (12:00h to $18: 00 \mathrm{~h})$ and night-time (00:00h to $06: 00 \mathrm{~h})$ periods of the ECG recordings containing at least $95 \%$ of pure sinus rhythm. Multifractal spectrum $\tau$ at $\mathrm{q}=3(\tau(\mathrm{q}=3))$, the peak position of the singularity spectrum (h_top) and the width of the singularity spectrum $(\Delta \mathrm{h})$ were calculated by wavelet modulus maxima method as proposed by Ivanov et al. Mean differences over time were tested using pairedsamples t-test. Results are reported as mean \pm SE; $p<0.05$ or less was considered significant.

\section{Results}

Preoperatively, $\tau(\mathrm{q}=3)$ was $-0.52 \pm 0.18$ and $-0.49 \pm 0.17$, h_top $0.20 \pm 0.07$ and $0.15 \pm 0.07$ and $\Delta \mathrm{h} 0.31 \pm 0.14$ and $0.71 \pm 0.14$ for day-time and night-time period, respectively. Postoperatively, $\tau(\mathrm{q}=3)$ was significantly higher for day-time period $(-0.43 \pm 0.23, \mathrm{p}=0.015)$, whereas h_top and $\Delta \mathrm{h}$ were significanly higher for both, day- and

\footnotetext{
* Correspondence: jus.ksela@kclj.si

${ }^{1}$ Department of Cardiovascular Surgery, University Medical Center Ljubljana, Slovenia

Full list of author information is available at the end of the article
}

night-time periods $(0.25 \pm 0.07, \mathrm{p}<0.001$ and $0.19 \pm 0.06$, $\mathrm{p}=0.002$ for $\mathrm{h} \_$top and $0.41 \pm 0.20$ and $0.31 \pm 0.19$ for $\Delta \mathrm{h}$, respectively).

\section{Conclusions}

Significant postoperative increase of all multifractal parameters, except of $\tau(\mathrm{q}=3)$ for night-time periods, clearly indicates that a marked breakdown of multifractal behavior into monofractal can be observed following off-pump CABG, indicating that multifractality is mostly governed by vagal activity.

\section{Authors' details}

${ }^{1}$ Department of Cardiovascular Surgery, University Medical Center Ljubljana, Slovenia. ${ }^{2}$ Department of Communication Systems, Jozef Stefan Institute, Ljubljana, Slovenia.

Published: 11 September 2013

doi:10.1186/1749-8090-8-S1-0109

Cite this article as: Ksela et al:: Multifractality of the heartbeat dynamics after beating heart myocardial revascularization. Journal of Cardiothoracic Surgery 2013 8(Suppl 1):0109.

Submit your next manuscript to BioMed Central and take full advantage of:

- Convenient online submission

- Thorough peer review

- No space constraints or color figure charges

- Immediate publication on acceptance

- Inclusion in PubMed, CAS, Scopus and Google Scholar

- Research which is freely available for redistribution 